\title{
It Takes a Community to Resurrect a CLS Program
}

\author{
JULIE HAMMERLING, BRENDA VAN DER HEYDEN
}

\begin{abstract}
Florida Gulf Coast University (FGCU) revised and reactivated its former $2+2$ NAACLS accredited program in 2006, by instituting an innovative $3+1$ approach. With the efforts of the community laboratories, FGCU instituted an innovative structure which made its CLS program more viable by greatly reducing expenses of operation without sacrificing the quality of education.
\end{abstract}

ABBREVIATIONS: CLS = Clinical Laboratory Science; FGCU = Florida Gulf Coast University; BS = Bachelor of Science; NAACLS = National Accrediting Agency for Clinical Laboratory Sciences; ASCP = American Society for Clinical Pathology; ETA Employment and Training Administration

INDEX TERMS: Clinical laboratory science education; clinical laboratory science training programs

Clin Lab Sci 2011;24(1):22

Brenda Van Der Heyden, BS, CLCP(NCA), MT(ASCP), Florida Gulf Coast University, Ft. Myers, FL 33965

Julie Hammerling, MS, CLS(NCA), MT(ASCP), Florida Gulf Coast University, Ft. Myers, FL 33965

Address for Correspondence: Julie Hammerling, Florida Gulf Coast University, College of Health Professions, 10501 FGCU Blvd. South, Ft. Myers, FL 33965, (239) 590-7453, (239) 590-7494 (fax), email: jhammerl@fgcu.edu.

\section{Program History}

In 1991, the Florida Legislature passed a bill authorizing the establishment of the tenth university in the educational system for the State of Florida. The new university would serve the ever-growing population of Southwest Florida. The city of Ft. Myers was chosen as the site for this new institution. As the plans progressed, community leaders were asked for input in shaping the future of the university, based on the needs that were identified by those leaders.

Health care needs were clearly identified in those early discussions. Based on the community voice, programs were approved for many health care areas, including a baccalaureate program for Clinical Laboratory Science. Recruiting for a program director began in 1996, well before construction was completed on the campus site. The University began admitting students in 1997. After two years of planning curriculum and hiring faculty, the CLS program accepted its first students in 1998. The department of Clinical Laboratory Science was housed within the College of Health Professions. The program was set up as a $2+2$ program following the common pattern throughout the country.

The University's plan was to serve a five county area of Southwest Florida, and the laboratory community within that area was eager about the prospect of having a CLS program (Figure 1). Until that time, the nearest laboratory programs of any kind, including two year programs, were located in the Tampa or Miami metropolitan areas of Florida. Both cities are at least a two hour drive from Ft. Myers. It had become increasingly difficult to recruit students in the secondary education system due to the lack of opportunities in the local community. Occasionally, a student would leave their home town to pursue an education in the laboratory field, but it often meant they would not return to the community to begin their careers. Additionally, many of the programs in Florida had closed or were in the process of closing, which further limited the options. Florida typically relies on individuals from the northern states seeking warmer climates, to fill the employment vacancies in the hospitals and reference labs. 


\section{CLINICAL PRACTICE}

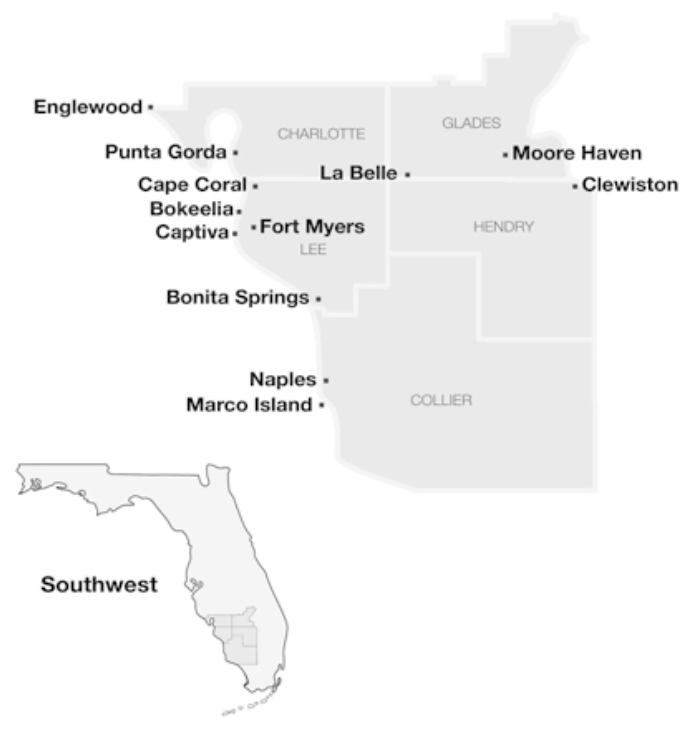

Figure 1: Counties of Southwest Florida in FGCU coverage area Source: http://www.florida-agriculture.com/consumers/regional_map. htm

The majority of the initial class were post-baccalaureate students. These students came from the ranks of the biology and chemistry graduates who were finding it difficult to secure jobs. Because Florida has a rigorous licensure requirement, most of these recruits were forced to settle for phlebotomy or pre-testing job duties, since they had no clinical training as part of their degrees. Gradually, the number of undergraduate students rose. The total number of enrolled students, including both post-baccalaureate and bachelors degree seeking students, held at about 10-15 per year.

As the university continued to grow and resource utilization came under closer scrutiny, the competition for classroom and laboratory space became issues. Maintaining the necessary faculty required to service a relatively low enrollment level of students was difficult to defend to administration. It appeared that the program faced the same fate as many other programs around the country, even though the faculty were involved in teaching other standard academic courses as well as the clinical lab courses. A decision was made by administration to move the program from the College of Health Professions to the College of Arts and Sciences, and hold new admissions pending a decision on the program's future. By the end of 2004, the decision was made to end the program by the University. The program would provide completion to the presently enrolled students, but once those students graduated, the program would end. The CLS faculty was absorbed into the sciences by the College of Arts and Sciences.

This decision was met with much distress within the laboratory community. Several of the hospital laboratory management teams met to discuss a strategy on how to maintain a viable program at the University. Further meetings involved the Interim Dean of the College of Arts and Sciences, leaders of the Southwest Florida Workforce Development Board, Inc., as well as community leaders in the laboratory arena and the former CLS Program Director.

There was considerable support to continue the program from all participants at the meeting; however, no one had a clear suggestion for an action plan. The Interim Dean suggested that if funding could be obtained for the Program Director's position, there would be a possibility to give the program one more chance. After 3 years, if student enrollment numbers were adequate to support program expenses, the University would consider continuation. This would assume that the only full time permanent position the University had to maintain would be the Program Director. It also assumed that the affiliated clinical sites were willing to provide all of the clinical training, reducing the need for laboratory space at the University.

During 2005, a core committee of laboratory managers met once a month for almost a year. The committee explored various options and outcomes for the program. Participants agreed to solicit the support of each hospital administration to fund the program. The approximate funding needed for a Program Director would be $\$ 100,000$ per year (for 3 years). The group began to solicit funds with that goal in mind, and accepted any amount of financial assistance that could be provided.

The core committee also examined 6 different CLS programs from around the country. Each committee member contacted a program director to find out how their program was structured, and asked for advice on 


\section{CLINICAL PRACTICE}

Table 1. 2005-06 Regional Targeted Occupations List (Sorted by Occupational Title)

Workforce Region 24 - Charlotte, Collier, Glades, Hendry, and Lee Counties

Workforce Estimating Conference Region 24 Selection Criteria:

1 FLDOE Training Codes 3 (PSAV Certificate) and 4 (Community College Credit/Degree)

225 annual openings and positive growth

3 Mean Wage of \$11.01/hour and Entry Wage of \$8.96/hour

4 High Skill/High Wage (HSHW) Occupations:

Mean Wage of $\$ 17.27 /$ hour and Entry Wage of $\$ 11.01 /$ hour

\begin{tabular}{|c|c|c|c|c|c|c|c|c|}
\hline \multirow[b]{2}{*}{ SOC Code } & \multirow[b]{2}{*}{ HSHW } & \multirow[b]{2}{*}{$\begin{array}{c}\text { Occupational } \\
\text { Title }\end{array}$} & \multirow{2}{*}{$\begin{array}{l}\text { Annual } \\
\text { Percent } \\
\text { Growth }\end{array}$} & \multirow[b]{2}{*}{$\begin{array}{c}\text { Annual } \\
\text { Openings }\end{array}$} & \multicolumn{2}{|c|}{ 2008 Hourly Wage } & \multirow{2}{*}{$\begin{array}{c}\text { FLDOE } \\
\text { Training } \\
\text { Code }\end{array}$} & \multirow[b]{2}{*}{$\begin{array}{l}\text { Data } \\
\text { Source }\end{array}$} \\
\hline & & & & & Mean & Entry & & \\
\hline 292011 & HSHW & $\begin{array}{l}\text { Medical and } \\
\text { Clinical } \\
\text { Laboratory } \\
\text { Technologists }\end{array}$ & 2.46 & 439 & 20.89 & 16.75 & 4 & $S$ \\
\hline
\end{tabular}

FLDOE=Florida Department of Education

Data Source:

$S$ = Meets statewide wage and openings criteria based on state Labor Market Statistics employer survey data. Statewide data are shown.

Source: Florida Agency for Workforce Innovation, Labor Market Statistics http://www.workforceflorida.com/partners/tol/index_05-06.htm

pursuing concerns with university administrators. Most of the committee members were familiar with the $3+1$ program structure. None of the area hospitals expressed a desire to run their own hospital-based programs. Hospital administrators preferred that the hospital labs would be providing a supportive role as they did before.

A needs assessment was initiated. All identified laboratories in the five county area determined how many positions may be needed in the future. The survey asked for the number of potential laboratory workers who were approaching retirement age and what the expected increase in demand would be for new positions in the next 5-10 years. The Workforce Board of Florida also provided annual projection data on careers and jobs by the state regions that are served by this agency. That data indicated a projected growth in the needs for clinical laboratory technologists in this area to be $2.5 \%$ annually. ${ }^{1}$ See Table 1 for 2005-2006 statistics from this region.

Once all the data was collected, and there was a commitment for funding from three of the largest hospitals in the area, two of the lab management members met with the University Deans of Health Professions and Arts and Sciences. Based on the data presented and discussions about curriculum, both deans were in agreement that the viability of the program should be reviewed once again. The Dean of the College of Arts and Science was in favor of moving the program back into the College of Health Professions. This meeting was the turning point for the current program.

\section{Redesign of Program Curriculum}

The previous CLS program was originally offered through the College of Health Professions and subsequently the College of Arts and Sciences. The program staff included a department chair/program director, 5 full time faculty members, and 1 faculty assistant. The current program is housed once again within the College of Health Professions, and staffed only by a program director and 4 adjunct faculty members. This staffing change was a big cost savings for the University.

Nationally, there are two basic program formats. The $2+2$ program, in which clinical practice is integrated 


\section{CLINICAL PRACTICE}

throughout the upper division coursework (junior and senior years), and includes training in on-campus student laboratories and off-campus clinical practice sites. Students take their didactic coursework by attending lecture and laboratory sessions in each area of lab study on campus, before they go out to their practice sites for their internships. This design gives the students exposure to all subjects before they are actually out in practice, but it also requires the program expense of laboratory instruments and supplies by the University. This was the format for FGCU's previous program. The lecture/lab courses at FGCU were offered in the traditional face-to-face format, which required the students' attendance on the university campus.

The other basic CLS program format is the $3+1$. In this format, clinical practice and didactic courses in the CLS major are taken in the student's senior year. The students are located at clinical practice sites during this year, for various amounts of time, depending on the individual program. The number of clinical practice weeks in the Florida State University System varies from 18 to 49 weeks.

FGCU's current program is a variant of the $3+1$ format whereby all of the didactic courses are offered online, with concurrent clinical practice training in the student's senior year. FGCU's program has no oncampus student laboratories. The students never have to come to FGCU campus. Students take 3 didactic courses each semester, for a total of 3 semesters in the final year. Most student rotation schedules at their practice sites follow the didactic course sequence, which seems to be the way most students and clinical instructors prefer. But, with higher student enrollment numbers, this becomes harder to accomplish as multiple students are assigned to the same site. In this case, students may not necessarily be in the same practice rotation as their didactic courses. This may make it slightly more difficult for students and instructors alike, but not impossible. It is also very important to inservice affiliated laboratories on evaluation criteria and competency assessment for students, as well as obtaining frequent progress reports on student performance.
Both previous and current CLS programs offered postbaccalaureate certificate programs. These programs were designed for students who had baccalaureate degrees in the areas of biology or chemistry, and had met the prerequisite requirements for CLS. The main difference between the previous and current design is the fact that students had to come to campus for face-to-face classes under the previous program.

In both of the FGCU CLS program formats; students could start their clinical practice at any one of the three semester starting points: Fall, Spring or Summer. This is always seen as an advantage by the student. Students don't have to wait for a single annual admission point, but it tends to add more work for program administration. Courses in the CLS major, during both previous and current, were offered only once per year. If a student had to repeat a course, they had to wait an entire year to retake it. Both programs had the requirement of getting a grade of " $\mathrm{C}$ " or better in every course.

The course curriculum for the current program kept the previous CLS courses, with minor changes. Three one credit courses were eliminated and the total credits for the degree dropped from 126 to 123 . See course curriculum in Tables 2,3 and $4 .^{2}$

Under the previous program, the Bachelor of Science degree consisted of 3 concentrations: Clinical Laboratory Science, Pre-Professional/Biotechnology and Forensic Science. Students in the CLS concentration combined didactic coursework with clinical practice in their degree requirements. Students in the PreProfessional/Biotechnology track had slightly different didactic coursework with research credits included, but no clinical practice experience. Therefore, these students, when finished, were not eligible to sit for CLS certification exams. Students in the Forensic Science track differed again in didactic coursework, and they had a forensic internship portion in their degree requirements. Students were allowed to combine concentrations and complete two concentrations by taking the additional required coursework.

The previous CLS program graduated a large portion of pre-professionals, but some of these students found that 


\section{CLINICAL PRACTICE}

they had no career to fall back on if they could not get accepted into professional schools. By taking the BS in CLS, students have the benefit of meeting professional school admission requirements, and greater employment options, if they do not continue on the path to professional schools for some reason.

Table 2. Current Program Requirements: State-Mandated Common Prerequisites

\begin{tabular}{|c|c|c|c|}
\hline Number & Course & $\begin{array}{l}\text { Credit } \\
\text { Hours }\end{array}$ & $\begin{array}{c}\text { Recommended } \\
\text { FGCU } \\
\text { Courses }\end{array}$ \\
\hline BSC 1XXX/1XXXL & General Biology w/lab & 4 & $\begin{array}{l}\text { BSC } \\
1010 \mathrm{C}\end{array}$ \\
\hline BSC $2 X X X / 2 X X X L$ & Anatomy \& Physiology I & 4 & $\begin{array}{l}\text { BSC } \\
1085 \mathrm{C}\end{array}$ \\
\hline BSC $2 \mathrm{XXX} / 2 \mathrm{XXXL}$ & Anatomy \& Physiology II & 4 & $\begin{array}{l}\text { BSC } \\
1086 C\end{array}$ \\
\hline CHM 1XXX/1XXXL & General Chemistry I & 4 & $\begin{array}{l}\text { CHM } \\
1045 \mathrm{C}\end{array}$ \\
\hline CHM 1XXX/1XXXL & General Chemistry II & 4 & $\begin{array}{l}\text { CHM } \\
1046 \mathrm{C}\end{array}$ \\
\hline CHM 2XXX/2XXXL & Organic Chemistry I & 4 & $\begin{array}{l}\text { CHM } \\
2210 \mathrm{C}\end{array}$ \\
\hline CHM 2XXX/2XXXL & $\begin{array}{l}\text { Organic Chemistry II or } \\
\text { Quantitative Analysis }\end{array}$ & 4 & $\begin{array}{l}\text { CHM } \\
2211 \mathrm{C}\end{array}$ \\
\hline MCB 2XXXC & Microbiology w/lab & 4 & $\begin{array}{l}\text { MCB } \\
3020 \mathrm{C}\end{array}$ \\
\hline $\begin{array}{l}\text { STA X023 or } \\
\text { STA X122 }\end{array}$ & Statistics & 3 & $\begin{array}{l}\text { STA } 2023 \\
\text { or STA } 2037\end{array}$ \\
\hline
\end{tabular}

Table 3. Current Program requirements: Required Courses for the B.S. in Clinical Laboratory Science

\begin{tabular}{|c|c|c|}
\hline COURSE & COURSE & COURSE \\
\hline NUMBER & TITLE & CREDIT \\
\hline IHS 3101 & $\begin{array}{l}\text { Shaping Health Care in the } \\
21 \text { st Century }\end{array}$ & 3 \\
\hline IHS 3203 & $\begin{array}{l}\text { Management and Leadership } \\
\text { in Health Care Organizations }\end{array}$ & 3 \\
\hline IHS 4504 & Research Methods in Health Care & 3 \\
\hline IHS 4938 & $\begin{array}{l}\text { College of Health Professions } \\
\text { Senior Seminar }\end{array}$ & 3 \\
\hline IDS 3920 & University Colloquium & 3 \\
\hline BCH 3023C & Biochemistry & 3 \\
\hline PCB 4233C & Immunology* & 3 \\
\hline PCB 3063C & Genetics* & 3 \\
\hline
\end{tabular}

The current CLS program has only one track, the traditional CLS. Some of our graduates continue on to other programs, such as pharmacy school, etc. Many of our current certificate students are those who had an original plan to attend medical school or other professional schools. By far, the greatest numbers of students currently admitted are graduates with degrees in biology.

Table 4. Current Program Requirements: Additional Required Courses

\begin{tabular}{llc}
\hline COURSE & COURSE & COURSE \\
NUMBER & TITLE & CREDIT \\
MLS 4191 & Molecular Diagnostics & 3 \\
MLS 4404 & Diagnostic Microbiology & 3 \\
MCB 4462 & Diagnostic Virology/Mycology/Parasitology & 3 \\
MLS 3038 & Essentials of Clinical Laboratory Science & 3 \\
MLS 3220 & Biological Fluid Analysis & 2 \\
MLS 4308 & Hematology/Hemostasis & 3 \\
MLS 4505 & Clinical Immunology & 2 \\
MLS 4550 & Immunohematology and Transfusion Practice 3 \\
MLS 4627 & Clinical Biochemistry & 3 \\
MLS 4820C & Clinical Biochemistry Practicum & 3 \\
MLS 4821C & Clinical Microbiology Practicum & 3 \\
MLS 4822C & Clinical Hematology /Hemostasis Practicum & 3 \\
MLS 4823C & Clinical Immunohematology Practicum & 3 \\
MLS 4826C & Clinical Immunology Practicum & 2 \\
\multicolumn{4}{l}{$\begin{array}{l}\text { Additional required courses in Clinical Laboratory Science (total B. S. } \\
\text { program length }\end{array}$} & 123 credit hours) and required courses for the post \\
baccalaureate certificate (total certificate program length 39 credit hours). &
\end{tabular}

\section{Clinical Affiliates}

The previous program had 4 main affiliates providing clinical training. Three of these sites were large enough to take multiple students at a time. The current program has expanded the number of main affiliates to 12 , and the coverage area expanded to 2 more counties - Sarasota and Broward (Figure 2). Current affiliates train fewer students, mainly due to the reduction in clinical staff from years past. The ability to take on more distant affiliate sites was made possible by our online format of didactic instruction. Future plans include out-of-state affiliations.

\section{Accreditation}

The previous program was NAACLS accredited in 2000. The program suspended admissions as the decision was being made to close the program. The last student under the previous program graduated in 2005 and accreditation was then suspended. In 2006, reactivation of the program was initiated. A new self 


\section{CLINICAL PRACTICE}

study was submitted in March 2008 and a site visit was conducted in November 2008. The NAACLS board

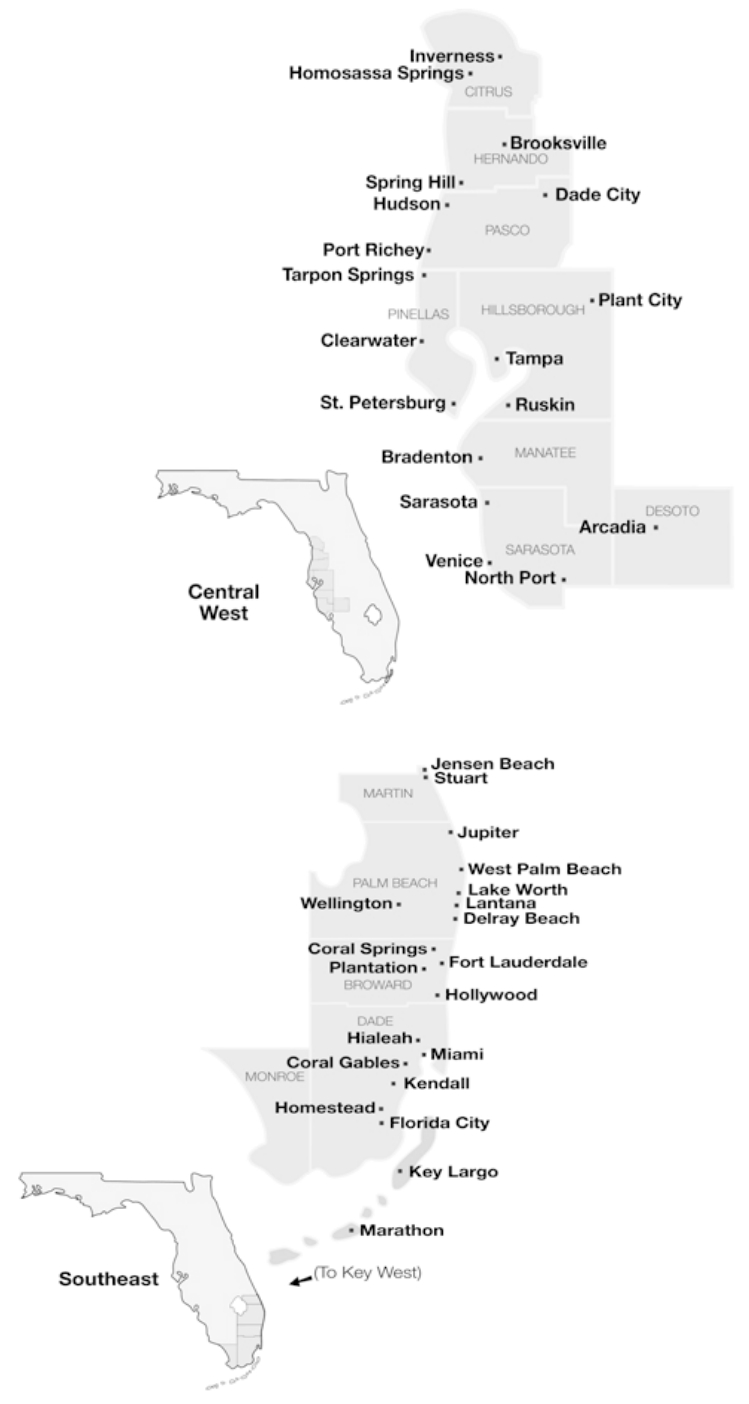

Figure 2: Additional counties added: Sarasota: Central West Florida, and Broward: Southeast Florida

Source: http://www.florida-agriculture.com/consumers/regional_ map.htm

granted full accreditation for 5 years (the longest allowable), in April 2009. Surveyors emphasized the following strengths of the program:

1. Dedicated Program Director who is devoted to the program and the students.

2. Supportive University administration and faculty.

3. Students and graduates have pride in the program and chosen profession and spoke highly of the program director.
4. The medical laboratory community is commended for advocating and responding to a need to address the local workforce shortage.

5. The Advisory Committee is committed to the success of the program and works collaboratively in maintaining the quality of the program.

6. The curriculum is supplemented with well structured case studies and interactive discussions in almost all areas of instruction.

\section{Cost Savings}

The cost savings that were realized in the redesign of the program were substantial. The decrease in faculty from 5 to 1 was a significant cost savings. The other area of cost savings was the fact that there were no on-campus student labs, with no expense for lab supplies or equipment. No on-campus classroom space was required under the current program.

\section{Enrollment}

The previous program graduated 25 students in 4 years, which included not only CLS majors, but also preprofessional/biotechnology majors who went on to medical, veterinary and physician assistant schools.

Initially, the enrollment goal for the current program for undergraduate degree seeking students was set at 10, along with 5 certificate students. In the first year (Summer 2007-Spring 2008) the program admitted 10 students and graduated 8 (all certificates). Two students dropped out of the program. At the end of year 2, there were 17 students in the program, graduating 14 and losing 3 students. Currently, there are 21 students in their clinical internships and about 25 undergraduate pre - CLS majors. There is a large amount of interest from the post-baccalaureate population due to the present economic conditions and the push to enter a more secure field such as health care.

\section{Pass Rates}

Data is unavailable for the previous program. In the first year of the current program (2008), the pass rate on the ASCP national certification exam was $87.5 \%$. This number is based on a low number of students. All passing students immediately began employment. Almost without exception, the clinical affiliates speak very highly of the students within the program, and are 


\section{CLINICAL PRACTICE}

quick to offer employment at the conclusion of their training program. Pass rates for year two is currently at $100 \%$.

\section{Importance of the Community Advisory Council}

Having incredible community support was very important in the resurrection of the program and its continuing success. The NAACLS surveyors commended both the medical laboratory community and particularly the Community Advisory Council for their part in maintaining a successful and quality program. The CLS Community Advisory Council is composed of a very dedicated and enthusiastic group of laboratory professionals. The council meets once per semester to discuss program and curricular issues. As membership on the Council has increased and distant affiliates have been added, a phone bridge system is now used to get maximum participation in the meetings.

\section{Outlook}

As enrollment continues to meet and exceed set goals, the future outlook for the FGCU CLS program is excellent. The University has now taken over the funding for the program and has made the Program Director's position permanent.

\section{REFERENCES}

1. Florida Workforce Region 24: 2005-06 Targeted Occupations List. Available from http://www.workforceflorida.com/ partners/tol/index_05-06.htm. Accessed 2009 Dec 2.

2. FGCU Clinical laboratory science curriculum. Available from http://www.fgcu.edu/CHP/HS/CLSBS/degreq.asp. Accessed 2009 Dec. 2.

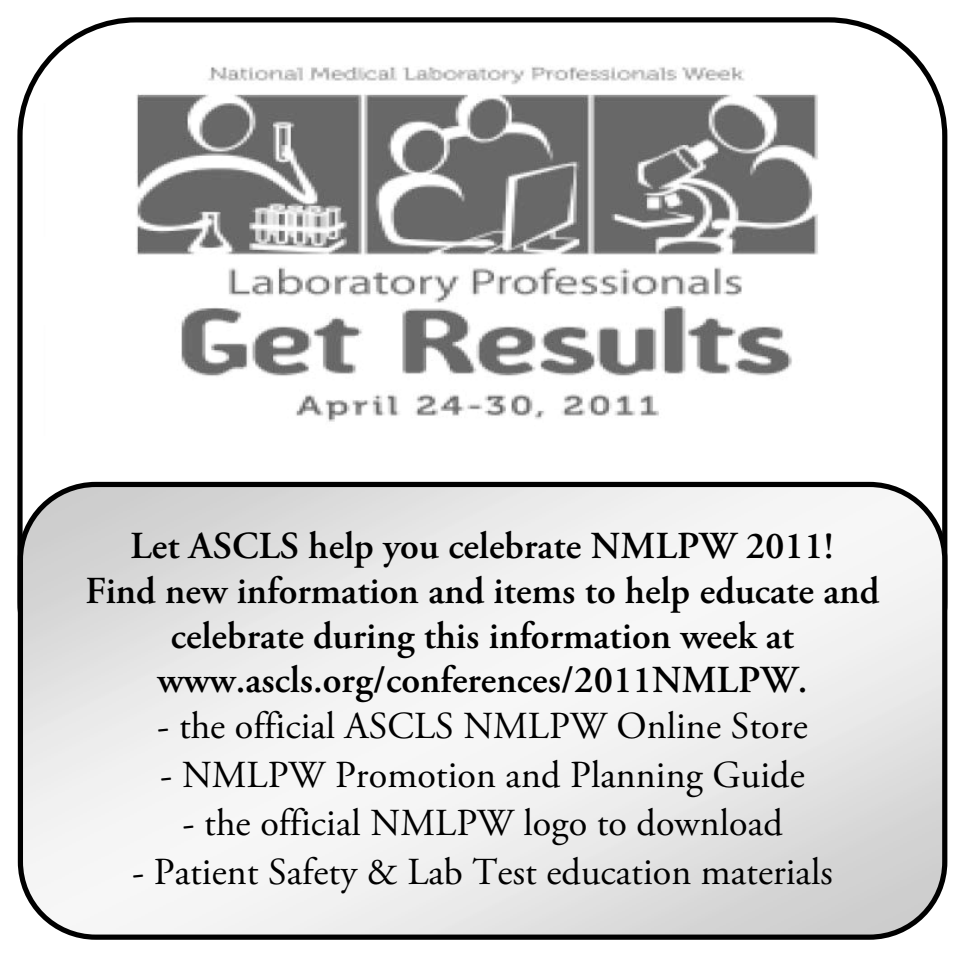

